\title{
PROCESSOS COTIDIANOS DE ORGANIZAÇÃO DO TRABALHO NA FEIRA LIVRE ${ }^{1}$
}

\author{
Leny Sato \\ Universidade de São Paulo, São Paulo, Brasil
}

RESUMO: Esse artigo tem por objetivo descrever algumas feições dos processos cotidianos que organizam o trabalho na feira livre. Partindo da compreensão de que tais processos têm sua substância em interações simbólicas, a pesquisa empírica foi desenvolvida por meio de convivência em uma feira livre da cidade de São Paulo, valendo-se também de dados secundários e de entrevistas. Como mercado de trabalho, estima-se que a feira livre gere trabalho e renda para cerca de quarenta mil pessoas. A feira livre organiza-se em redes de relações sociais e suas principais feições são: mesclar relações de trabalho com as familiares, de vizinhança e de amizade; acionar suas rotinas valendo-se de regras tácitas e operar por meio de relações de cooperação e de competição. Os processos que organizam a feira livre devem ser compreendidos à luz da posição da feira livre no processo de urbanização dos países subdesenvolvidos.

PALAVRAS-CHAVE: Psicologia Social; Psicologia do trabalho; feira livre; trabalho; processos organizativos; rede de relações sociais.

\section{DAY-TO-DAY ORGANIZATIONAL PROCESSES OF WORK AT THE OPEN STREET MARKET}

ABSTRACT: This article aims to describe some features of the everyday processes that organize work at the open street market. It assumes that symbolic interactions are the substance of these processes. The empirical study was conducted by means of the ethnographic approach in an open street market at São Paulo (Brasil). As a labor market, the open street market provides jobs and incomes for about forty thousand workers. The open street market is organized as a social network, and its main features are: to mix labor relationships with friendship, neighbour and family relationship; to be informed by tacit rules and to be sustained by cooperation and competitiveness. The processes that organize the open street market must be understood in face of the process of urbanization in underdeveloped countries.

KEYWORDS: social psychology, psychology of work, open street market, work, organizational processes, social network.

O objetivo desse artigo é descrever algumas feições dos processos cotidianos que organizam o trabalho na feira livre. Para tanto, apresento a um breve histórico da feira livre, o método empregado, a leitura que orienta a compreensão dos processos organizativos, a descrição dos processos cotidianos que organizam a feira livre e as considerações finais.

\section{A feira livre na vida da metrópole}

A origem da feira livre remonta o século IX na Europa: os mercados locais organizados com vistas a suprir a população local com os gêneros de primeira necessidade (Pirenne, 1936).

No nosso caso, em São Paulo, a oferta de produtos alimentícios experimentou diversos tipos de comércio varejista em diferentes momentos de sua história: as quitandas, os mercados, os vendedores ambulantes (Guimarães, 1969; Kozlowski, 1976). A feira livre é oficializada em 1914, tendo sido uma reivindicação do movimento grevista de 1917, conforme depoimento de Edgard Leuenroth, importante líder anarquista desse movimento, ${ }^{2}$ como meio de baratear a oferta de gêneros de primeira necessidade (Pinheiro \& Hall, 1979).

Atualmente a cidade de São Paulo abriga cerca de novecentas feiras livres semanais, de terça-feira a domingo.
São instaladas nos diversos bairros da cidade, situando-se em locais com características econômicas e sócio-culturais diferentes. Como mercado de trabalho, estima-se que gere renda para aproximadamente quarenta mil pessoas. $\mathrm{O}$ número de comerciantes por feira livre é variável, mas há feiras que acolhem mais de cem unidades produtivas (bancas de propriedade do feirante titular), além dos feirantes ambulantes e muitos trabalhadores que vivem da oferta de pequenos serviços (carregadores, vendedores de lanches e refrigerantes, vendedores de rifa, trocadores de dinheiro para os feirantes etc.).

Passado quase um século desde a sua criação, a posição da feira livre no comércio varejista de alimentos in natura mudou significativamente com a crescente instalação de super e hipermercados. A década de 60 do século que passou testemunhou a expansão dos supermercados (Jesus, 1991). Esse crescimento acompanhou mudanças importantes no processo de urbanização da cidade de São Paulo.AAssociação Brasileira de Supermercados (ABRAS) estima que atualmente cerca de $40 \%$ do abastecimento de produtos hortículas é realizado por supermercados, porcentagem que conta com a distribuição de cinco grandes redes de supermercados (Souza, De Rezende \& Prado, 2001). 
Para compreender a posição da feira livre no espaço da metrópole, recorro à teoria de Milton Santos (1979/2004) sobre o processo de urbanização dos países subdesenvolvidos, a qual toma os diversos tipos de atividade econômica e ocupacional para compreendê-lo. Para o autor, esse processo caracteriza-se pela divisão do espaço urbano em dois circuitos econômicos. $\mathrm{O}$ "circuito superior" engloba as atividades econômicas ditas "modernas", voltadas para a acumulação de capital, como os grandes conglomerados orientados pela economia global; incorpora tecnologia de ponta, emprega trabalhadores com nível de escolarização/qualificação mais elevado; as atividades de comércio voltam-se para segmentos das classes média e alta. Por sua vez, o "circuito inferior" orienta sua atividade para a população e economia locais; é trabalhointensivo utilizando tecnologia pouco sofisticada; os vínculos de trabalho são precários em termos de proteção social; a atividade comercial dirige-se, prioritariamente, para as camadas médias e populares e visa, também prioritariamente, garantir a sobrevivência. Por ser hegemônico, o "circuito superior" da economia orienta as regras para o funcionamento do "circuito inferior" também, o que pode ser sentido como uma convivência tensa.

No caso específico, a tensão entre o comércio da feira livre e o das grandes redes de super e hipermercados ${ }^{3}-$ exemplares do comércio varejista de alimentos alocados no "circuito superior" - é constantemente relatada pelos feirantes. Não éà toa que os feirantes trazem, espontaneamente, o tema da extinção da feira livre. As ameaças sentidas vêm de longa data. A pulverização dos supermercados freqüentemente é considerada a causa da queda de movimento das feiras livres. ${ }^{4}$

Muito embora haja distinções significativas entre os dois circuitos, suas atividades convivem e se influenciam mutuamente. A feira livre - característica de atividade situada no "circuito inferior" - escoa produtos oferecidos por importadores (grandes atacadistas) e tem como fregueses pessoas dos estratos sociais médios e altos. Além disso, observa-se que os supermercados buscam reproduzir a estética da feira livre e, em alguns casos, também o atendimento personalizado, característico da feira livre.

O espaço urbano é permeado pelo trânsito entre as atividades dos dois circuitos da economia.

Esses aspectos possibilitam situar os processos que cotidianamente organizam e fazem a feira livre.

\section{Para conhecer a feira livre}

Muitas são as concepções sobre o que é "organização". Morgan (1986) emprega diversas metáforas para apresentá-las: máquina (taylorismo-fordismo), cérebro (cibernética), prisões psíquicas (psicanálise) e sistemas de governo (política) são algumas delas.

A concepção aqui adotada é devedora de leitura que toma as pessoas em interação simbólica como as constru- toras dos processos organizativos. Não são, entretanto, construtoras que têm diante de si a liberdade incondicional para fazer o quê e como quiserem. São pessoas situadas em lugares, defrontando-se com regras, valores, projetos e metas definidos de modo autônomo ou heterônomo; são pessoas posicionadas em degraus hierárquicos diferentes ou não; com maior ou menor amplitude de poder para definir os rumos do que se pretende organizar, os objetivos da empreitada bem como os caminhos adotados. Vale lembrar, ainda, que são interações simbólicas desenroladas tendo-se em vista a dimensão técnica à disposição (equipamentos, máquinas, procedimentos etc.) e o ambiente sócio-econômico e cultural no qual se insere. ${ }^{5}$

Assim, compreendo "organização" como "fluxos de ações e significados" (Spink, 1991). Parte-se do pressuposto que tais processos encontram a sua racionalidade interna e singular nos métodos práticos, criados, apropriados e partilhados pelas pessoas envolvidas, fazendo das feiras livres, no caso, realidades "organizadas" (Garfinkel, 1967/1994; Sato, 2002; Tedesco, 1999). A leitura focaliza os fazeres cotidianos, as interações simbólicas nos pequenos agrupamentos e o burburinho que desdobra frutos e os avoluma para além da relação dual; privilegia as interações simbólicas que se sustentam na cultura, nos costumes e nos acordos possíveis e não a estrutura técnicofuncional (Lanzara, 1985).

Projetar e construir uma casa, por exemplo, pode ser
um processo puramente técnico ou pode ser um pro-
cesso em grande parte ritual: a estrutura de plane-
jamento nos dois casos é completamente diferente,
os elementos componentes são diferentes, os crité-
rios de seleção são diferentes, as regras para a compo-
sição dos elementos e os significados atribuídos às
regras e às ações são diferentes... O resultado do
planejamento - a casa - pode ser visto como o pro-
duto de um processo sustentado por uma estrutura
decisional, ou como fruto de uma análise funcional,
ou como um universo de elementos simbólicos evo-
cados e produzidos, compatíveis mediante um cerimo-
nial conduzido coletivamente (Lanzara, 1985, p. 60
e 61 ).

Descrever tais processos, portanto, requer a construção dos significados que sustentam as atividades observadas, não se restringindo à descrição dos fenômenos que se encontram na superfície de suas manifestações. Trata-se de construir uma descrição densa (Geertz, 1989).

Alinhado a essa concepção, o método adotado deve ser capaz de apreender os fazeres que se dão no dia-a-dia, na relação dual, nos pequenos encontros, nos comentários pontuais e restritos, e nas conversas alongadas e públicas (Sato \& Souza, 2001). Para tanto, realizei estudo etnográfico: convivência prolongada numa feira livre da cidade de São Paulo (SP), valendo-me de dados secundários e de entrevistas. $\mathrm{O}$ recurso à fotografia também foi adotado 
e minha presença com a câmera e o oferecimento de fotografias relevadas foram importante instrumento para lograr maior proximidade com os feirantes, freguesas e habitués da feira livre.

A feira livre estudada situa-se no bairro Vila Mariana, de classe média, na zona sul da cidade de São Paulo. Instalada às sextas-feiras, a “feira da Caixa D'Água”, como é conhecida pelos feirantes - porque situa-se próximo a uma caixa d'água da companhia de saneamento do estado -, congrega cerca de cento e cinqüenta bancas, em torno de quatrocentos e sessenta feirantes, com aproximadamente setecentos metros quadrados de banca. Em termos metodológicos, qualquer feira livre poderia ser adotada para aprofundar o conhecimento sobre o seu cotidiano. Feiras diferentes em diferentes bairros exibirão feições também diferentes, pois elas se fazem com as características do lugar, adjetivando seus processos organizativos; porém suas feições substantivas podem ser apreendidas em qualquer uma delas e assim compreendendo, escolhi uma feira, ainda que incursões esporádicas a outras fossem feitas.

\section{Organização, Trabalho e Sociabilidade}

Para se compreender os processos que cotidianamente são conduzidos para organizar a feira livre é importante identificar as regras gerais de seu funcionamento.

Está a cargo da Secretaria Municipal de Abastecimento (SEMAB) da Prefeitura de São Paulo a definição de normas e a fiscalização das feiras livres. Regulamentos definem o conjunto de regras referentes à instalação, tipos e grupos de mercadorias que podem ser comercializados, regras de higiene, dentre outras. ${ }^{6} \mathrm{~A}$ autorização para trabalhar como feirante é concedida pela SEMAB que define o rol de feiras livres nas quais o feirante titular (detentor de autorização) pode trabalhar, de terça-feira a domingo. Característica estrutural importante é o fato de as feiras instalarem-se no espaço público e serem itinerantes.

\section{Espaço público, estético e lúdico}

Feira significa festa. As famosas feiras da Idade Média - que se assemelhavam às nossas feiras regionais - reuniam mercadores dos diversos locais nas datas de festas religiosas, ocasiões nas quais os comerciantes faziam seus negócios. Thompson (1967/1998) mostra como a disciplina do trabalho encontra como contraponto o ambiente das feiras, espaço de ócio e de lazer. Esse significado social encontra-se presente nas nossas feiras livres: local de comércio, de trabalho e de sociabilidade. ${ }^{7}$

A configuração e os usos habituais dos logradouros nos quais as feiras se instalam são transformados em outra coisa.

As dimensões estética e lúdica da feira livre são feições importantes desse comércio que jogam papel pragmático com vistas a interferir na definição de compra da fregue- sia. No entanto, tais dimensões não podem ser reduzidas a essa finalidade.

Mesmo cercada de amplas avenidas que conduzem os destinos e sentidos da metrópole, a instalação da feira livre garante um certo isolamento que autoriza a criação de um espaço no qual a brincadeira, o chiste e as regras de civilidade (Elias, 1939/1994a) podem conviver publicamente com as intenções da metrópole, como um mundo ritual, no qual as coisas "adquirem um sentido diferente e podem exprimir mais do que aquilo que exprimem no seu contexto normal" (DaMatta, 1990, p. 63). Nos dizeres de um dos feirantes (Marcos), a feira livre autoriza que o "protocolo" seja quebrado. Para isso, um palco é criado: a chegada dos feirantes na madrugada trazendo seus equipamentos, mercadorias e montando suas bancas vai, paulatinamente, construindo também suas vitrines. Após algumas horas um espaço protegido, circunscrito pelas bancas, dá o substrato para os fazeres e interações sociais que ali têm lugar. Esse palco funciona como uma marcação para que os desvios de sentido dos fazeres, das interações e das práticas sejam evitados. Assim, chamar as freguesas de "linda", "menina" e "minha querida" não significa que os feirantes as estejam galanteando. Do mesmo modo, "meter a colher em conversa alheia" faz parte dos comportamentos "normais" na feira livre.

Cores, formas e texturas das mercadorias são exploradas pelos feirantes garantindo resultado estético que conta com a apreciação de freguesas e feirantes. Fotografias tiradas no decorrer do trabalho de campo permitiramme conhecer os comentários sobre o que é significativo para os feirantes: destaca-se, dentre os vários enquadramentos obtidos, a beleza construída com as mercadorias que fazem das bancas, vitrines. A arte cotidiana - elaborada com recursos pouco sofisticados mas adequados para apresentar as mercadorias - é fruto de um apurado senso estético que confere identidade à estética da feira livre, a qual, note-se, vê sua imitação nas grandes redes de supermercados. No exemplo a seguir vê-se a criação possível:

\section{Buquê-de-rúcula}

A rúcula é uma verdura de sabor pregnante e de cheiro inconfundivel, de um verde forte e vivo, homogêneo. 'É uma verdura que não precisa de tempero... ela já vem temperada', avalia Joana, a diarista que trabalha em minha casa.

As raízes dos pés de rúcula são arrancadas juntamente com as folhas. Muito finas e frisadas, as raízes, amarronzadas pelos restos de terra que carregam, prolongam-se das folhas verdes. De textura fibrosa, quase um cipozinho, as raízes são fortes o suficiente para suportarem a amarração.

Mauro cuida do terço inferior da banca de Alberto. Sempre está quieto, em seu 'pedaço' e, desde que o conheci, nunca o vi parado. De cabeça baixa, limpa, seleciona e 're-maça' as folhas verdes das rúculas, 
e o faz de um modo singular: unindo todos os fiapos de raizes, ata os pezinhos de rúcula, num amarrilho de folha de embira. Os maços de rúcula feitos por Mauro são inconfundíveis. Não são maços, são buquês. Deixam as folhas verdes livres, e rijas, ficam espetadas.

E quem iria duvidar que, nesse trabalho rotineiro, algo repetitivo, cansativo, há singularidade, há o belo e deposita-se afeto?

(fragmento do diário de campo).

Feirantes são performers. Característico da feira livre, o horário da xepa imanta todos os seus significados: trabalho, comércio, beleza, brincadeira e o chamamento eloqüente da freguesia. Embora para muitos feirantes e fregueses a feira seja apenas local de trabalho e de comercialização e, por isso, não participem das performances, são os performers que chamam a atenção.

Ao comunicar a uma amiga de infância que já trabalhou na feira livre, que desenvolveria pesquisa sobre o tema, assim ela exclamou: "você vai estudar a feira livre?... Ih, você vai se divertir muito!". Comentando a leitura de alguns trechos do relato dessa pesquisa, Alberto, um verdureiro, conclui: "feirante é um pouco palhaço, um pouco artista... um pouco de tudo. Lendo seu trabalho a gente sente que tem uma profissão".

Beleza e brincadeira são trabalho.

\section{Rede como forma organizativa}

Marcos define a feira livre como uma "bagunça organizada", expressão que compatibiliza duas formas organizativas aparentemente antagônicas em que a anarquia (capacidade organizativa autônoma) convive com uma suposta padronização centralmente definida.

As regras bastante genéricas emanadas pela SEMAB deixam um campo aberto para que os feirantes organizem a convivência e construam seus fazeres. Ademais, o nomadismo estrutural faz com que o feirante tenha que "montar uma loja todo dia" (Dinorah). E isso quer dizer muito mais que estar submetido ao trabalho fisicamente pesado de transporte, carregamento, montagem, arrumação e desmontagem da "loja". O nomadismo requer que os feirantes se situem e convivam em ambientes sociais, econômicos e culturais diferentes, garantidos pelos perfis da freguesia e pela convivência com feirantes diferentes em cada lugar. A cada dia o feirante situa-se em um campo social diferente (Lewin, 1943/1963, 1936/1973).

A característica desse comércio é justamente possibilitar um número infinito, e sempre renovado, de acordos construídos a cada hora, a cada circunstância e a cada problema que se apresente em cada "loja". É um processo organizativo que se caracteriza como um "fenômeno reticular", como afirma Elias (1987/1994b). ${ }^{8}$ Isto porque no decorrer desse processo, cada um dos interlocutores forma idéias que não existiam antes e leva adiante idéias que já estavam presentes. Mas a idéia e a ordem seguidas por essa formação e transformação das idéias não são explicáveis unicamente pela estrutura de um ou outro parceiro, e sim pela relação entre os dois. E é justamente esse fato de as pessoas mudarem em relação umas às outras e através de sua relação mútua, de se estarem continuamente moldando e remoldando em relação umas às outras, que caracteriza o fenômeno reticular em geral (Elias, 1987/1994b, p. 29).

Ao mesmo tempo, a depender da feira onde se instala, a banca de um mesmo feirante poderá portar feições bastante distintas, que fazem o observador duvidar que seja o mesmo feirante. Se essa não é a regra geral, ela informa a amplitude das possibilidades desse trabalho itinerante, o qual, para ser compreendido, demanda a adoção de uma leitura relacional (Lewin, 1943/1963, 1936/1973).

Apreender a rede de relações sociais que configura a feira livre demandou seguir os fios e identificar os "nós" que tecem sua organização. Desenhar essa organização implicou em apreender os acontecimentos que envolviam conversas reservadas, o burburinho e os debates mais amplos. Muito embora localizados, os diversos acontecimentos davam notícias sobre os fenômenos considerados "normais" na feira livre. Nos dizeres de Marc Augé:

\begin{abstract}
o sentido social não se identifica com a soma que uma cosmologia representa ou com a teoria social, com o conjunto de normas do jogo social cuja lista um informante habilmente solicitado pode reconstituir e fornecer. Esse senso só se atualiza nos enunciados particulares que especificam as relações entre parceiros diferentes da vida social. São enunciados circunstanciais que fazem alusão aos relacionamentos normais [grifos nossos] (quer dizer culturalmente simbolizados e admitidos) entre um pai e seu filho mais velho, um irmão e uma irmã, um marido e uma esposa, uma tia materna e um sobrinho uterino, etc. Esta 'normalidade' não se limita às relações de parentesco e se esperam da parte dos parceiros da vida social, econômica, política, comportamentos globalmente conformes com os tipos de conduta simbolizados e instituídos na e pela sua sociedade (Augé, 1994/1999, p. 43).
\end{abstract}

Nessa rede, os fluxos de interação simbólica não estão norteados por um centro a partir do qual emanam as informações, os motes das conversas e as decisões. Os "fios" que ligam as pessoas entre si estendem-se em diversas direções. A estrutura da rede de relações sociais e de significados pôde ser apreendida, mas a posteriori (Mayer, 1966/1987).

A rede abriga e é construída pela presença de várias lógicas que se encontram em um lugar, em um dia da semana e se espalham em várias outras feiras livres nos outros dias e em outros lugares. Em pequenos espaços e 
num determinado tempo há maior densidade de encontros que dão substância a essa organização, construindo, questionando e repondo continuamente as regras, os valores e a cultura. Baseia-se na troca de idéias, de pontos de vista, de argumentos e de experiências. A feira livre deve ser compreendida, então, como um contínuo organizar, baseado em acordos e negociações, em cooperação e competição e na execução de regras tácitas. Isso garante a agilidade, a extrema adaptabilidade e a criatividade de formas de se fazer a feira livre.

As relações de trabalho mesclam-se com relações familiares, de amizade e de vizinhança no bairro de moradia. As relações interpessoais na feira livre são norteadas por diversas gramáticas (DaMatta, 1985). Regras de convivência familiar se fazem presentes no espaço de trabalho, tanto no sentido de garantir a proteção contra a aplicação fria e impessoal da "letra de lei", o código da rua (DaMatta, 1985), como no de exigir a manutenção do respeito à hierarquia familiar no contexto de trabalho. Vizinhos no bairro de moradia podem experimentar posições de ajudante e patrão, e amigos podem trabalhar como ajudantes na mesma banca. Vê-se, entre os ajudantes, intensa rotatividade pelas diversas bancas. Um ajudante pode trabalhar para várias "firmas" no decorrer da semana. A feira livre é notória por abrigar vínculos precários de trabalho em termos de proteção social (Guimarães, 1969; Santos, 1979/ 2004).

Por ser tecida por essa diversidade de vínculos, a rede de relações pessoais encontra outros espaços para formar os seus "nós": a casa, o bairro e os diversos centros atacadistas. Acompanhando Marcos a um desses centros, ele diz: "se você quiser encontrar feirante, vem aqui na segunda-feira", evidenciando que os acordos que organizam a feira livre também são feitos em outros lugares. Ao mesmo tempo, alude à potência dessa rede no que se refere à agilidade para espraiar informações e para orientar as tomadas de decisão.

"Feira livre tem que ter feirante", diz Celso, feirante há mais de vinte anos. A ausência episódica de alguns feirantes e o abandono de outros é motivo de preocupação pois pode indicar que o próprio negócio está em risco. Além disso, essa frase, aparentemente óbvia, conduz ao universo de significados sobre a convivência coletiva de vários micro-empresários (feirantes titulares) e seus ajudantes, os feirantes ambulantes e um sem número de trabalhadores que vivem da feira livre. Ela remete à necessidade de convivência entre diversas pessoas com livreiniciativa, à possibilidade de construção de acordos e à manutenção de um tênue equilíbrio entre relações cooperativas e competitivas.

A proximidade geográfica possibilita o estabelecimento de acordos entre vizinhos de banca. Entre si constroem regras de convivência específica, em geral válidas apenas para os feirantes que as definem, sendo impraticável qualquer tentativa de generalização. Elas englobam desde a definição de horários de montagem e desmontagem das bancas até a faixa de preços praticados.

Relações de cooperação e de competição com os feirantes de uma mesma feira são observadas e podem mesmo ocorrer em momentos contíguos. Para servir a "sua" freguesa, eventualmente Dona Jurema socorre-se na banca de Zico tomando-lhe a mercadoria que lhe falta; mas, no momento seguinte, pode dirigir-lhe comentários que apontem o quão reprovável foi a sua decisão de praticar preços tão baixos - "marretar", segundo o vocabulário dos feirantes -, pois os demais feirantes não podem acompanhálo. Mas, se a presença do concorrente pode ser incômoda, aos olhos de alguns, ela é necessária.

Eu preciso que na feira tenha outros feirantes que comercializem a mesma mercadoria que eu... a freguesa compara os preços; aquele feirante lá embaixo, vende a mercadoria mais cara que eu, pode até ser que ele venda mais do que eu, mas se só tivesse eu aqui que vendesse ovo, a freguesa não saberia se eu tô vendendo caro ou barato (Juca).

A ausência episódica de um feirante vizinho foi sentida por Juca, que explicava seu "ar desanimado". Essa falta explica o menor fluxo de fregueses nesse segmento da feira. E dizia:

quando tem essa banca aqui na frente, as freguesas passam aqui e a gente só dá uma chamadinha, elas olham e se aproximam; quando não tem, é chato gritar, a freguesa tá lá do outro lado, ela não vem do lado de cá só pra ver a minha banca.

Muitos acordos e desentendimentos na feira livre acontecem explicitamente a partir das conversas, das discussões e dos chamamentos em voz alta, mas a manutenção da rotina depende do conhecimento e do compartilhamento do significado do discurso social que se entranha no reino do não-dito. São as regras que apenas se expressam quando são executadas.

Para ser feirante é necessário adquirir qualificações de natureza técnica, digamos assim, que dizem respeito à capacidade de conduzir economicamente o "negócio"; mas é também, ou acima de tudo, compreender o texto social que o tempo todo está impresso nos pequenos fazeres, mas que não se oferece com um guia de interpretação. Para os que estão imersos no métier, nem sempre é possível explicitá-lo verbalmente pois está tão próximo deles mesmos como a pele do corpo que não se destaca e nem sequer percebem que os constitui. Para os que estão imersos na rede de significados, "ser" é ser assim, condição que não se presta facilmente ao distanciamento, ao estranhamento e ao questionamento. Como aponta Garfinkel (1967/1994), as regras tácitas são explicitadas quando o fluxo normal dos acontecimentos sofre uma ruptura. 
Estar imerso no métier significa compreender o que se passa à sua volta. Assim:

\begin{abstract}
... 'compreender' o significado das ações e comunicações dos outros como uma prática qualificada, constitui um elemento integrante das capacidades de rotina de atores sociais competentes, e é essa competência que os fazem ser membros. A hermenêutica não é apenas um recurso privilegiado do investigador social profissional, mas é praticada por todos; o domínio dessa prática é a única via pela qual tanto cientistas sociais profissionais quanto os próprios atores leigos se tornam capazes de elaborar descrições da vida social a que recorrem em suas análises (Giddens, 1998, p. 291)
\end{abstract}

É esse o desafio vivido por Juca. Embora há cerca de dois anos trabalhando como feirante, considera-se um novato. Diferentemente da maioria dos colegas, ele não descende de uma família de feirantes e não havia trabalhado anteriormente no ramo. $\mathrm{O}$ aprendizado das regras e dos "segredos" da profissão tem ocorrido no dia-a-dia, por tentativa e erro, sem contar com a ajuda de qualquer preceptor. Alcançar a condição de membro no universo da feira livre é um longo e sofrido processo pois não é incomum que o estrangeiro só as conheça no momento mesmo em que as regras são executadas.

“É duro de aprender, o pessoal não dá um toque" (Juca). E relata um exemplo dessas regras não ditas, mas executadas. Era o seu primeiro dia de trabalho na "feira da Caixa D’Água”. Ao final da feira trouxe sua Kombi para perto do local em que monta a sua banca para guarda-la. Já desmontada, Juca, calmamente, recolhe seus pertences. E relata seu desespero:

\begin{abstract}
Aí eu vejo aquele caminhãozão chegando e eu tendo que guardar as coisas rapidinho; só que você vê o espaço que tem aqui [que permite a passagem apertada de um caminhão por entre as bancas] $e$ eu desesperado, carregando a Kombi. Só que pra mim sair, eu tive que andar de ré uns 300 metros. Foi o maior sufoco! E o pessoal olhando.
\end{abstract}

Hoje, relatando esse episódio, ele ri. "Na outra semana, o pessoal, me chamava: aí, porteira!”, pois fechara o caminho para que os caminhões adentrassem o espaço. Aqui percebeu-se enredado e concluiu que sua agenda pessoal tinha que ser coordenada à dos outros. No entanto, raros foram os dias em que fossem presenciadas conversas para definir os ajustes necessários por ter havido descompasso nesse ritmo. Comumente, os feirantes recebem sinalizações importantes por meio do movimento das outras bancas, dos feirantes, dos caminhões e das kombis. E basta isso para sinalizar o que podem ou o que devem fazer.

\section{"Você já tá pegando o espírito da coisa!"}

Nem sempre é fácil para a freguesia encontrar vaga para estacionar seus automóveis. Aguardo um tempo na esperança de encontrar uma boa vaga, mas, com a demora, recebo a seguinte orientação do guardador de carro:

- 'Deixa ele aqui na frente mesmo, você só vai embora com eles!'

Estaciono na frente de um caminhão, que, para sair, depende da retirada de meu carro.

No final da feira, enquanto Juca desmontava sua banca, conversamos. De sua banca consigo acompanhar o movimento dos feirantes junto a seus caminhões: arrumam a carga, transportam caixotes, tabuleiros e cavaletes. $O$ vai-e-vem de feirantes é contínuo.

Num determinado momento, interrompo nossa conversa:

- 'Espera um pouco Juca, vou tirar o meu carro, o Edílson já tá no caminhão', e saio. No meio do caminho encontro Edílson:

- 'Esse carro é teu?'

- 'É, já vim tirar.'

Após alguns minutos, Edílson parte com seus irmãos no caminhão.

Quando retorno, Juca analisa:

'Você já tá pegando o espírito da coisa!'

(fragmento de diário de campo)

Incluídas nessas regras estão as referentes à ética do trabalho. Rafael aponta uma gafe cometida por Neide. Ao ver um de seus fregueses aproximando-se da banca de seu vizinho, também fruteiro, Neide chama o freguês pelo nome enquanto adentra o espaço da banca vizinha. Com um abacaxi e uma faca em mãos, como se trabalhasse na banca de seu vizinho, Neide "dá prova" do abacaxi ao freguês. $\mathrm{O}$ feirante, dono dessa banca, ao seu lado, parecendo surpreso, não reage, apenas observa a situação. Rafael, que trabalha na mesma banca de Neide, vendo o comportamento da colega, brincando, fala alto para o feirante: "dá um tapa na orelha dela!". E continuando a conversar comigo, ele explica: "Isso que a Neide fez, não se faz". Havia, aqui, a necessidade de Rafael dar mostras ao vizinho de que reconhecia que aquele era um procedimento por ele reprovado pois conhece a ética que rege o métier.

A rede faz-se do acompanhamento dos acontecimentos por todos e o olhar é um importante sentido. Saber-se olhado é um mínimo de contra-controle que os feirantes podem ter, pois a própria arquitetura das bancas reserva pouco espaço para a área vedada a olhos alheios. Não há paredes, embora haja bastidor. Alguns feirantes falam sobre a necessidade de ter uma visão de trezentos e sessenta graus. Olhar de "rabo de olho" é um expediente adotado; outros indicam que alguém olhou por eles, dando notícias de acontecimentos que não presenciaram. A visão panorâmica não é um privilégio de ninguém: olhar e ser olhado é condição à qual todos estão submetidos e dela podem fazer uso. 
As regras e os acordos que fazem a rede de relações sociais permitem que as circunstâncias ofereçam a ocasião para a adoção de táticas, mostrando que uma feira pode ganhar diferentes feições, algo corriqueiro e perfeitamente possível. Seu Frederico é um feirante antigo e já idoso. Montava sua pequena banca no setor de verduras e frutas. Após algum tempo, ele estava com sua pequena banca montada em outro local, defronte aos pescados, uma boa localização para ele, que vende limão. Foi possível mudar a posição de sua banca em função de o feirante para o qual aquele local é destinado, ter abandonado a feira. Passadas algumas semanas, ele dividia espaço com outra banca que vendia tomates, verduras etc. A depender da circunstância, três locais diferentes podem abrigar a banca de Seu Frederico.

Feirantes que estão posicionados em locais considerados não muito movimentados da feira aproveitam os espaços deixados por feirantes que excepcionalmente faltam em determinadas ocasiões: próximo ao carnaval ou outros feriados prolongados. Surpresa por ver Eli, um ajudante de banca de frutas, em outro lugar, pergunto-lhe se ele havia mudado de banca.

Não. É que hoje o fruteiro que monta aqui não veio e a gente montou a nossa aqui. Esse japonês [o feirante faltoso] é o que tem as melhores frutas e a melhor freguesia nessa feira. Ele é careiro... Aí a gente montou aqui pra ver se pega um pouco da freguesia dele...

Essas mudanças encontram justificativa que repousa no fato de posicionarem-se em locais de maior movimento, mas, além dessa, muitos alegam que é muito ruim deixar "buraco" na feira pois a "feira fica feia". E um "buraco" interfere no movimento daquele segmento da feira, pois "a freguesa só vai até ali e volta, não vem até o fim da feira”.

\section{Um primeiro fechamento}

A feira livre como espaço de trabalho faz-se da beleza, da brincadeira e move-se num mundo ritual, o que faz sobressair sua dimensão como espaço de convivência social.

Valendo-se da prerrogativa de ser uma atividade itinerante e de acontecer no espaço público, a feira livre caracteriza-se por estruturar-se numa ampla rede de relações sociais que mescla diversas gramáticas sociais e vale-se de regras tácitas. A dinâmica dá-se por meio de relações de cooperação e de competição. A amplitude dessa rede alarga-se para diversos lugares além daqueles nas quais as feiras livres se instalam e se corporifica no chão do cotidiano por meio de conversas entre vizinhos de banca, no burburinho e nos debates mais amplos.

O livre arbítrio de cada um é moldado e depende da existência dos outros. As possibilidades de organização da feira livre dão-se de acordo com cada situação, cada lugar e cada circunstância.

A rede como forma organizativa garante agilidade na transmissão de informações e uma notável adaptabilidade em seu funcionamento. Um mesmo feirante pode ter sua banca com feições bastante diferentes nas diversas feiras que faz e uma mesma feira também pode ser bastante diferente a depender das circunstâncias. A auto-regulação é garantida pelos próprios feirantes à luz do ambiente social, cultural e econômico no qual a feira é instalada. Tal dinâmica recusou a proposta da secretária do Sindicato dos Feirantes de São Paulo, de alçar um dos feirantes à posição de gerente da feira livre.

É na trama da rede de relações sociais que os feirantes constroem seus respectivos "sistemas de trabalho" (Alberto), forjando a organização do processo de trabalho de cada unidade produtiva, âmbito que foge aos propósitos desse artigo.

A sociedade em rede é tema presente, discutido, sobretudo, no contexto do atual desenvolvimento tecnológico informacional que agiliza a transmissão de informações e a tomada de decisões na sociedade globalizada mediante relacionamentos virtuais (Castells, 2002). No caso da feira livre, a rede também mostra a sua potência, mas ela reside na conservação de sua singularidade, na qual as relações face a face, as conversas e os encontros diários prescindem de mediações tecnológicas sofisticadas para acontecer.

\section{Notas}

1 Esse artigo é resultado parcial de pesquisa desenvolvida com apoio de bolsa de produtividade em pesquisa concedida pelo CNPq. Comunicação pessoal de Paul Singer.

Os sacolões e varejões também são uma presença incômoda para os feirantes, mas é incomparável com as redes de super e hipermercados.

4 Jesus (1991) aponta que em 1989, cerca de 78,2\% do volume de alimentos comercializados no varejo, no Brasil, era feito pelos supermercados.

5 Aqui a Escola Sociotécnica (Kelly,1978; Spink, 1979) é uma referência importante no sentido de estabelecer que os processos organizativos estão sustentados em duas dimensões: a social e a técnica. A técnica, decerto, não é imutável e é um produto humano. A teoria de campo de Kurt Lewin (1943/1963, 1936/1973) é uma importante referência na qual pessoa e ambiente devem ser tomados simultaneamente para a compreensão dos processos interacionais. Note-se que por ambiente entende-se aquele socialmente construído também, estando aí incluídas, portanto, as dimensões políticas e econômicas.

6 Está em vigor o decreto número 41.918 de 2002, que "Dispõe sobre o funcionamento das feiras livre no Município de São Paulo e dá outras providências" (São Paulo, 2002).

7 Vedana (2004) desenvolve estudo na feira livre da Empresa PortoAlegrense de Turismo (EPATUR), na cidade de Porto Alegre, enfatizando as artes de fazer de feirantes e consumidores, no qual fica evidente o espaço de sociabilidade criado na feira livre.

8 Norbert Elias (1987/1994b) busca ultrapassar a dicotomia indivíduo-sociedade e, para isso põe ênfase nas relações pessoais 
que se dão no dia a dia. As noções de fenômeno reticular e de rede são importantes em seu projeto teórico. Elias denomina de rede "a totalidade da relação entre indivíduo e sociedade" (p. 30).

\section{Referências}

Augé, M. (1999). O sentido dos outros-Atualidade da Antropologia. Petrópolis, RJ: Vozes. (Original publicado em 1994)

Castells, M. (2002). A sociedade em rede - A era da informação: Economia, sociedade e cultura. Rio de Janeiro, RJ: Paz e Terra.

DaMatta, R. (1985). A casa e a rua: Espaço, cidadania, mulher e morte no Brasil. São Paulo, SP: Brasiliense.

DaMatta, R. (1990). Carnavais, malandros e heróis: Para uma sociologia do dilema brasileiro. Rio de Janeiro, RJ: Guanabara.

Elias, N. (1994a). O processo civilizatório: Volume 1. Uma história dos costumes. Rio de Janeiro, RJ: Jorge Zahar. (Original publicado em 1939)

Elias, N. (1994b). A sociedade dos indivíduos. Rio de Janeiro, RJ: Jorge Zahar. (Original publicado em 1987)

Garfinkel, H. (1994). Studies in Ethnomethodology. Cambridge, MA: Polity Press. (Original publicado em 1967)

Geertz, C. (1989). A interpretação das culturas. Rio de Janeiro, RJ: LTR.

Giddens, A. (1998). Política, sociologia e teoria social. Encontros com o pensamento social clássico contemporâneo. São Paulo, SP: Fundação Editora da Universidade Estadual Paulista.

Guimarães, O. (1969). O papel das feiras livres no abastecimento da cidade de São Paulo. Dissertação de Mestrado não-publicada, Instituto de Geografia, Universidade de São Paulo, SP.

Jesus, G. M. (1991). O lugar da feira livre na grande cidade capitalista: Conflito, mudança e persistência (Rio de Janeiro: 1964 1988). Dissertação de Mestrado não-publicada, Instituto de Geociências, Universidade Federal do Rio de Janeiro, RJ.

Kelly, J. E. (1978). A reappraisal of sociotechnical systems theory. Human Relations, 31(12), 1069-1099.

Kozlowski, I. (1976). O significado da feira livre no espaço urbano de São Paulo. Trabalho de Graduação Interdisciplinar, Faculdade de Arquitetura e Urbanismo, Universidade de São Paulo, SP.

Lanzara, G. F. (1985). La progettazione: da analisi funzionale ad attività dialogica-discursiva. In C. Ciborra \& G. F. Lanzara (Eds.), Progettazione delle nuove tecnologie e qualità del lavoro (pp. 3578). Milano, Italy: Franco Angeli.

Lewin, K. (1963). Definição de "campo num determinado momento". In D. Cartwright (Ed.), Teoria de campo em ciência social (pp. 69-98). São Paulo, SP: Pioneira. (Original publicado em 1943)

Lewin, K. (1973). Princípios de Psicologia Topológica. São Paulo, SP: Cultrix. (Original publicado em 1936)

Mayer, A. C. (1987). A importância dos "quase grupos" no estudo das sociedades complexas. In B. Feldman-Bianco (Ed.), Antropologia das sociedades contemporâneas: Métodos (pp. 127-193). São Paulo, SP: Global. (Original publicado em 1966)

Morgan, G. (1986). Images of organization. Newbury Park, CA: Sage.

Pinheiro, P. S., \& Hall, M. N. (1979). A classe operária no Brasil - 1889-1930. Documentos. São Paulo, SP: Alfa-Omega.
Pirenne, H. (1936). Economic and Social History of Medieval Europe. New York: A Harvest Book.

Santos, M. (2004). O espaço dividido - Os dois circuitos da economia urbana dos países subdesenvolvidos. São Paulo, SP: Editora da Universidade de São Paulo. (Original publicado em 1979)

São Paulo (2002, 18 abr.). Decreto n ${ }^{\circ} 41.918$. Dispõe sobre o funcionamento das feiras livre no Município de São Paulo e dá outras providências. Diário Oficial do Município de São Paulo, 47(72).

Sato, L. (2002). Prevenção de agravos à saúde do trabalhador: Replanejando o trabalho através das negociações cotidianas. Cadernos de Saúde Pública, 18(5), 1147-1166.

Sato, L., \& Souza, M.P.R. (2001). Contribuindo para desvelar a complexidade da vida cotidiana através da investigação etnográfica em Psicologia. Psicologia USP, 12(2), 29-47.

Souza, R. A. M., De Resende, J. V., \& Prado, T. A. (2001). Fornecedores paulistas organizam-se para negociar com o varejo. In Instituto de Economia Agrícola. Banco de textos: Políticas Públicas. Retirado em 09 ago. 2005, de http://www.iea.sp.gov.br/out/ verTexto.php?codTexto=533

Spink, P. (1979, set.). Teoria e prática no planejamento do trabalho: Reflexões acerca de uma área de confusão. Trabalho apresentado no II Seminário Internacional de Produtividade e Humanização do Trabalho. São Paulo, SP: Fundação Getúlio Vargas. Mímeo.

Spink, P. (1991). O resgate da parte. Revista de Administração, 26(2), 22-31.

Tedesco, J. C. (1999). Paradigmas do cotidiano: Introdução à constituição de um campo de análise social. Santa Cruz do Sul, RS: Editora da Universidade de Santa Cruz do Sul.

Thompson, E. P. (1998). Tempo, disciplina de trabalho e capitalismo industrial. In E. P. Thompson. Costumes em comum: Estudos sobre a cultura popular tradicional (pp. 267-304). São Paulo, SP: Companhia das Letras. (Original publicado em 1967)

Vedana, V. (2004). "Fazer a feira": Estudo etnográfico das "artes de fazer" de feirantes e fregueses da Feira Livre da Epatur no contexto da paisagem urbana de Porto Alegre. Dissertação de Mestrado não-publicada, Programa de Pós-Graduação em Antropologia Social, Universidade Federal do Rio Grande do Sul, Porto Alegre, RS.

Leny Sato é Livre-Docente em Psicologia pela Universidade de São Paulo (USP). Endereço para correspondência: Instituto de Psicologia, USP, Av. Prof. Mello Moraes, 1721, São Paulo, SP, 05508-000.

lenysato@usp.br

\section{Processos cotidianos de organização do trabalho na feira livre}

Leny Sato

Recebido: 12/07/2006

Aceite final: 22/10/2006 